\title{
EDITORIAL
}

\section{Difficulties in panic studies}

\author{
Donald F. Klein \\ Research Professor, New York University, Langone Medical Center Department of Child and Adolescent Psychiatry, New York, NY, USA.
}

In a previous editorial, ${ }^{1}$ it was discussed that much of the factual support for our understanding of panic disorder remains weak, the central reason being that the key studies have not been replicated. The present editorial, stimulated by two articles appearing in Revista Brasileira de Psiquiatria, ${ }^{2,3}$ reflects on other problems.

A major difficulty is the definition of panic, since this word has different referents in everyday usage, depending on the context. We reviewed many definitional difficulties some time ago, but unfortunately problems persist. $^{4}$

In DSM-IV, panic attack is defined "as a discrete period of intense fear or discomfort, in which four or more of the following symptoms developed abruptly and reached a peak within 10 minutes." There follows 13 well-recognized associated symptoms. This definition raises major difficulties. For instance, the term "intense" is quantitatively ambiguous, but plainly means more than slight. Conversely, in the definition of panic used in the two papers, the mere presence of a symptom counts. Also, it is not clear whether the symptoms recorded in a diary are or not restricted to panic occurrence.

Another major problem is the minimum cutoff at four symptoms. This was selected to ensure coverage, so that patients will not be left out. However, this increase in sensitivity results in decreased specificity. It should be noted that panic attacks, as occurring in longitudinally established cases of panic disorder, regularly endorse far more than four symptoms. Therefore, other conditions are often confused with panic.

Many different anxiety disorders are associated with strong anticipatory anxiety. In these cases, when confronted with a feared situation, there may be a crescendo of anticipatory anxiety. For instance, the social phobic who has to enter a crowded party may have a rush of palpitations, sweating, and tremor, as also occurs in ordinary fear, which may be confused with panic. It is striking that air hunger (dyspnea) is not associated with social phobia or ordinary fear. However, it is the panic that occurs "out of the blue" that is defining for panic disorder. Therefore, the minimum of four associated symptoms is a clinical estimate aiming at high sensitivity, but it is not scientifically definitive.

Freire et al. $^{3}$ hoped that the proportion of diaryspecified symptomatic "respiratory" complaints would predict carbon dioxide-induced panic, and found a

Correspondence: Donald F Klein, 1016 Fifth Ave, 10028, New York, NY, USA.

E-mail: donaldk737@aol.com significant correlation of 0.33 . However, this is far below the level necessary to be scientifically useful. The lack of significant correlations between the respiratory ratio and other possibly validating criteria further weakens the case for promising utility.

Stepping back from this detail, the question arises why this respiratory ratio measure was considered a likely predictor. It can be clinically difficult to elicit from patients the outstanding features of their panic attacks. It would not be surprising if diary recording would be very limited. To expect that, in a diary, the ratio of spontaneously recorded, respiratory-related panic symptoms to all panicrelated symptoms would be an effective predictor seems optimistic.

DSM-IV also refers to situationally predisposed panic. For instance, a patient may know that he is more likely to have a panic attack in a crowded supermarket, but this may or may not happen. Or the patient may be in the supermarket for some time before a panic attack strikes. It is noteworthy that both apparently spontaneous and situationally predisposed panics respond well to serotonergic antidepressants. This is not the case with situationally bound panics as occur in specific phobias. Should situationally predisposed panic be referred to as expected or unexpected? DSM-5 contributes to the confusion by eliminating the term situationally predisposed, reducing this concept to the ambiguous "expected or unexpected." The likelihood of diary entry of such panics is unknown.

Xerfan do Amaral et al. ${ }^{2}$ narrowly focus on studies of carbon dioxide-produced panic, starting in 1984. The authors' description of that decade focuses exclusively on the use of $35 \%$ carbon dioxide inhalation. However, they omit the key article, ${ }^{5}$ which (despite the title) compares the effects of $5 \%$ carbon dioxide inhalation, room air hyperventilation, and intravenous lactate in the same patients with panic disorder.

The background to that investigation ${ }^{5}$ is of interest. At the time, the leading hypothesis about the development of panic attacks was that of hyperventilation. It was known that acute hyperventilation caused acute respiratory alkalosis, and it was believed that somehow this was translated into a panic attack. We wished to test if respiratory alkalosis was necessary to cause panic during active hyperventilation. We knew that the level of carbon dioxide in the lungs approximated $5 \%$. It followed that, if a subject hyperventilated in a $5 \%$ carbon dioxide air environment, they would not develop respiratory alkalosis, as they would be in dynamic equilibrium. The experimental setup was a transparent computerized 
plethysmographic tent that measured both the frequency and tidal volume of each breath. Our expectations, in accordance with the conventional wisdom, were that subjects hyperventilating in room air would develop panic attacks, whereas those in $5 \%$ carbon dioxide would not.

To our substantial surprise, exactly the opposite occurred. Further, those who responded with panic to carbon dioxide were a subset of those who panicked to lactate. The few patients who panicked with hyperventilation had no correlation with lactate-induced panic.

We had learned that intravenous lactate causes panic attacks in patients with panic disorder without stimulation of the hypothalamic pituitary adrenal (HPA) stress response system. This was important because spontaneous clinical panic also did not stimulate the HPA system, thus allowing to distinguish between panic and acute fear. It was gratifying to find that the panic attacks initiated by both 5 and $7 \%$ carbon dioxide environments did not stimulate the HPA system. Early reports of $35 \%$ carbon dioxide inhalation did not refer to stimulation of the HPA system. Later studies quite clearly showed that the inhalation of $35 \%$ carbon dioxide does stimulate cortisol release. ${ }^{6}$ Therefore, the parallelism of $35 \%$ carbon dioxide-induced panic and spontaneous clinical panic is brought into question.

The brilliant twin work by Battaglia et al. ${ }^{7,8}$ using $35 \%$ carbon dioxide inhalations showed a clear genetic relationship between panic disorder, childhood separation anxiety, and carbon dioxide-induced panic attacks. The same team has also argued that the $35 \%$ carbon dioxide response implies two different genetic contributions. In my view, this supports the hypothesis that $35 \%$ carbon dioxide is a complex stimulus affecting both the suffocation alarm system and a system related to ordinary fear. Unfortunately, studies systematically varying carbon dioxide inhalation in patients have been displaced by the ease of single- or double-breath 35\% carbon dioxide inhalation.

The team led by Pine, ${ }^{9}$ studying anxious children, continues to show the utility of the $5 \%$ approach, which allows longitudinal physiological observations. Their findings illuminate the heterogeneity of separation anxiety disorder by relating carbon dioxide sensitivity to parental panic disorder.
In sum, limiting the study of panic to the various forms of carbon dioxide induction ignores the breadth of interrelated variables needed to improve our understanding of panic disorder. Factual compilations gain relevance by placing them in the context of alternative theories of pathogenesis. ${ }^{10}$

\section{Disclosure}

The author reports no conflicts of interest.

\section{References}

1 Klein DF. Panic developments. Rev Bras Psiquiatr. 2012;34:S1-2.

2 Xerfan do Amaral JM, Spadaro PT, Pereira VM, Silva AC, Nardi AE. Carbon dioxide challenge test in panic disorder: pre-clinical and clinical research - a systematic review. Rev Bras Psiquiatr. 2013;35:318-31.

3 Freire RC, Nascimento I, Valença AM, Lopes FL, Mezzasalma MA, de Melo Neto VL, et al. The panic disorder respiratory ratio: a dimensional approach to the respiratory subtype. Rev Bras Psiquiatr. 2013;35:57-62.

4 Klein DF, Klein HM. The substantive effect of variations in panic measurement and agoraphobia definition. Journal of Anxiety Disorders. 1989;3:45-56.

5 Gorman JM, Askanazi J, Liebowitz MR, Fyer AJ, Stein J, Kinney JM, et al. Response to hyperventilation in a group of patients with panic disorder. Am J Psychiatry. 1984;141:857-61.

6 Argyropoulos SV, Bailey JE, Hood SD, Kendrick AH, Rich AS, Laszlo $\mathrm{G}$, et al. Inhalation of $35 \% \mathrm{CO}(2)$ results in activation of the HPA axis in healthy volunteers. Psychoneuroendocrinology. 2002;27:715-29.

7 Battaglia M, Pesenti-Gritti P, Medland SE, Ogliari A, Tambs K, Spatola CA. A genetically informed study of the association between childhood separation anxiety, sensitivity to $\mathrm{CO}(2)$, panic disorder, and the effect of childhood parental loss. Arch Gen Psychiatry. 2009;66:64-71

8 Roberson-Nay R, Moruzzi S, Ogliari A, Pezzica E, Tambs K, Kendler $\mathrm{KS}$, et al. Evidence for distinct genetic effects associated with response to $35 \% \mathrm{CO}_{2}$. Depress Anxiety. 2013;30:259-66.

9 Roberson-Nay R, Klein DF, Klein RG, Mannuzza S, Moulton JL, 3rd, Guardino $\mathrm{M}$, et al. Carbon dioxide hypersensitivity in separationanxious offspring of parents with panic disorder. Biol Psychiatry. 2010;67:1171-7.

10 Preter M, Lee SH, Petkova E, Vannucci M, Kim S, Klein DF. Controlled cross-over study in normal subjects of naloxone-preceding-lactate infusions; respiratory and subjective responses: relationship to endogenous opioid system, suffocation false alarm theory and childhood parental loss. Psychol Med. 2011;41:385-93. 